\title{
Preliminary preparation of water supply system for the headbox through Pulsar water treatment plant
}

\author{
V. Dymchenko*, N. Petrusheva, E. Ilyazova, and M. Lipilin \\ Lesosibirsk branch of Siberian State Technological University of Science and Technology named \\ after Academician M.F. Reshetnev, 29 Pobedy str., Lesosibirsk, 662543, Russian Federation
}

\begin{abstract}
Today, the main quality criterion in the production of fiberboards is a uniform supply of mixed wood fiber slurry to the mesh part of the press using a high pressure headbox. The interaction of water, various inclusions of waste water, wood-fiber semi-finished product, as well as stainless steel provokes occurrence of chemical reactions that cause intense corrosive destruction of working parts of the inlet. At present, the study of corrosion of the inlet structure pursues the goal of determining characteristic factors caused by the aggressive environment arising at the time of mixing the wood-fiber suspension with the water flow. The analysis of fiberboard production by the wet method examines the possibility of introducing equipment designed for high-quality water treatment with the possibility of cleaning it from various impurities. Pulsar water treatment system is designed for oxidation of soluble metals with their conversion into filterable forms, cleaning from organic and inorganic contaminants due to filters of soft and coarse cleaning using AS sorbents. The station operates autonomously with control of the output gravity for up to 10 years with annual losses of no more than $10 \%$ of filter elements.
\end{abstract}

Today, the basis for production of wood fiberboards by the wet method is the technological process of separating the ground wood pulp into individual fibers, which provide a strong interconnection during the molding process.

Technological chips obtained from low-quality wood and wood waste of deciduous and coniferous species (aspen, spruce, birch, beech, pine and others) constitute the main technological base for production of fiberboards due to recrushing of waste in disk chippers. [1-3]

High-quality grinding makes it possible to prepare a semi-finished wood fiber product for mixing in a pressure device (Fig. 1), which will further increase binding characteristics of the finished product due to the smooth and even surface of the fiberboard, as well as to increased density and elasticity.

* Corresponding author: dymchenko-v98@mail.ru 


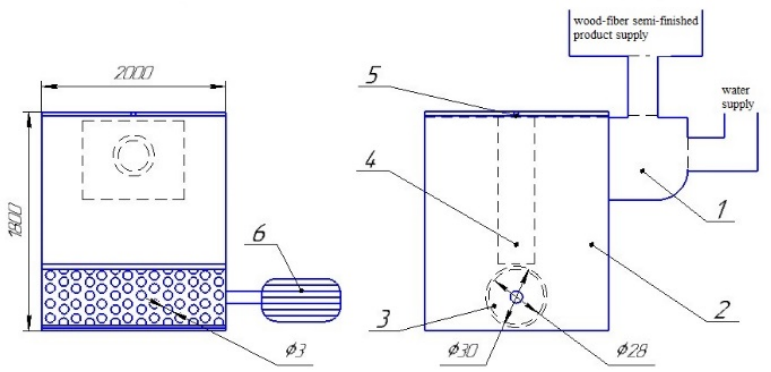

1 - collector; 2 - case; 3 - perforated shaft; 4 - shield; 5 - antifoam; 6 electric motor.

Fig. 1. Open headbox device for high pressure stock

Based on studies of the operation of the headbox as a feeder, it is possible to identify the main problem of molding wood fiber slurry onto the mesh part - this is work in an aggressive environment. An aggressive environment is an increased wear of the body and working elements made of stainless steel due to occurrence of chemical reactions between a ground semi-finished product, water, water impurities and stainless steel itself. [4-5]

By their nature, wastewater impurities can be divided into 3 main classifications: mineral, organic, and biological. In turn, organic are divided into plant, artificial and animal origin.

Mineral impurities include particles of sand, clay, ores, slags, mineral oils, salts, acids and various bases.

Organic plant impurities are called residues of plants, algae, their decomposition products, etc.

Animal contaminants include animal tissue residues, adhesives, etc.

An artificial origin of impurities includes residues of organic impurities formed from products of organic chemistry enterprises, food industry and many other types of industries. By the degree of solubility, impurities can be divided into insoluble and soluble.

Insoluble are also called suspended particles, they include particles of sand, clay, silt.

Soluble impurities can be in the form of colloids (occupying an intermediate position between suspended and dissolved substances) or truly soluble molecules and ions.

According to the analysis of water inclusions and impurities contained in wastewater, the main types of destruction of stainless steel were developed (Fig. 2). The destruction of stainless steel occurs due to electrochemical corrosion caused by chemical reactions. [6]

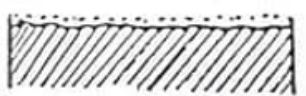

1

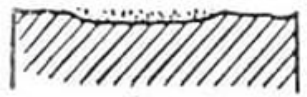

4

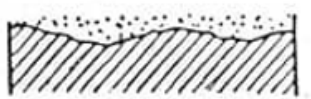

2

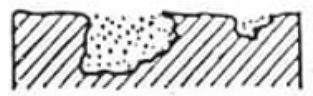

5

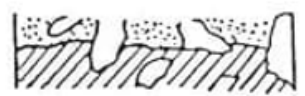

3

1 - uniform, 2 - uneven, 3 - selective, 4 - localized, 5 - pitting.

Fig. 2. Corrosion types of stainless steel inlets 
Uniform corrosion. Takes place over the entire surface of the steel headbox case and is accompanied by a slight loss of structural weight, which is not noticeable at first glance. The consequences of uniform corrosion have practically no effect on the mechanical strength of the inlet, however, conditions for the development of pitting corrosion increase.

Uneven corrosion. It is accompanied by the appearance of microscopic inhomogeneities due to the increased electrical conductivity of the water pressure. The unregulated head velocity creates diffusion difficulties in the working area of the headbox. As a result, at a fixed value of the water pressure supply, there is no possibility of saturation of all surfaces of the inlet with oxygen, leading to uneven corrosion.

Selective corrosion. The most effective development occurs in the construction of steel alloys, namely in the intercrystalline lattice of one of the metals included in the alloy. Appearance of this corrosion is accompanied by formation of intergranular or transcrystalline cracks.

Localized corrosion. This corrosion is caused by appearance of stains due to uneven aeration of the steel, which changes spatial separation of the ongoing reaction in the headbox due to formation of localization of the oxidation process.

Pitting corrosion. Destruction occurs due to formation of chemical reactions of a metallic environment and elements of aqueous impurities. This corrosion is manifested by small pits on the protective layer of stainless steel in places with the highest wear. A sharp decrease in the resistance of steels against pitting corrosion occurs when sulfide nonmetallic inclusions based on calcium are released in their structure. [7]

According to studies of the effect of electrochemical corrosion on stainless steel, Pulsar ozone filtering station was selected.

This station is selected according to the flow rate of water per hour passing through the station.

The operation principle of the filter station is taken from the technical passport of the management and operation of filtered plants. The initial water under pressure and with a flow rate determined by the parameters of the inlet's pressure is fed to the inlet of the filter station through the inlet valve of the bypass line and first enters the strainer - mud collector, where large particles larger than 300 microns are retained. Further, water goes through a full-bore flow meter, which regulates the amount of consumed water per column of the purification plant.

The purification plant is a sealed chamber where there is an intensive oxidation of water impurities (metals and organic compounds) under the action of an ozone-air mixture (OAM), as well as separation and removal of gas undissolved in water. The ozone-air mixture is generated in the ozonation unit from atmospheric air and, with the help of an air compressor through a high-pressure tube through a check valve, is pumped into the pipeline directly in front of the pressure columns. The ozonation unit and the air compressor turn on automatically when a water flow appears.

The water-gas mixture enters the inside of the columns through supply pipes, reaching approximately to its middle. In the thickness of the water layer, water bubbles with floating bubbles of OAM, and the undissolved gas accumulating in the upper part of the column is discharged through the air intake manifold and then through the ball valve and S-050 air valve to the ozone destructor.

Impurities in water, subject to oxidation, are converted into coarse particles and retained in the subsequent layers of the load with removal by the reverse flow of water. The main advantages of sorbents include:

1. service life up to 10 years with annual losses of $7-8 \%$, no more than $10 \%$ per year;

2. ability to remove hydrogen sulfide, which is oxidized to elemental sulfur and is retained in the loading layer; 
3. effective work at low pH values (from 6.0);

4. relatively small amount of water for flushing the filtering installation.

As a confirmation of the filtering station's performance, quantitative measurements of various inclusions were carried out before and after preparation of an aqueous solution using a detailed analysis of water in an accredited laboratory of the Krasnoyarsk Krai (Table 1).

Table 1. Sanitary and chemical indicators of waste water before and after filtration through an ozone-filtering station for water purification

\begin{tabular}{|c|c|c|}
\hline Indicator & Water before filtration & Water after filtration \\
\hline Uniform & Corrosion type & Corrosion type \\
\hline $\mathrm{pH}, \mathrm{mg} / \mathrm{l}$ & 8.4 & 3.34 \\
\hline Settling substances, $\mathrm{mg} / \mathrm{l}$ & 1.354 & 0.00157 \\
\hline Total iron, $\mathrm{mg} / \mathrm{dm}^{3}$ & 0.46 & 0.154 \\
\hline Manganese & 0.1 & 0.012 \\
\hline Permanganate oxidizability, $\mathrm{mg} / \mathrm{dm}^{3}$ & 3 & 0.8 \\
\hline COD, $\mathrm{mg} \mathrm{O}^{2} / \mathrm{l}:$ & 240 & - \\
\hline Color, $\mathrm{mg}^{3} \mathrm{dm}^{3}$ & 13 & 4 \\
\hline Ammonium & 28 & 21 \\
\hline Nitrates & 0.1 & 0.045 \\
\hline Ether-soluble substances, $\mathrm{mg} / \mathrm{l}$ & 63 & 12 \\
\hline Turbidity, mg/dm ${ }^{3}$ & 2 & 1.45 \\
\hline Surfactant, $\mathrm{mg} / \mathrm{l}$ & 3.5 & 2.1 \\
\hline
\end{tabular}

To maximize efficiency of the ozone-filtering installation and measuring equipment of the ozone-filtering stations, it is required to operate with the factory settings of the manufacturer. Transport by any type of transport in covered vehicles at any distance. During transportation and handling operations, the shipping container should not be exposed to sharp shocks and direct exposure to atmospheric precipitation and dust. Limiting conditions for storage and transportation:

1) ambient temperature from minus 25 to plus $55^{\circ} \mathrm{C}$;

2) relative air humidity not more than $95 \%$;

3) atmospheric pressure not less than $61.33 \mathrm{kPa}(460 \mathrm{~mm} \mathrm{Hg})$

The operation manual of the ozone-filtering station guarantees water purification due to the sorbents of filtering installations with the subsequent decomposition of iron, the content of which is less than $0.03 \mathrm{mg} / \mathrm{dm}^{3}$, manganese $0.01 \mathrm{mg} / \mathrm{dm}^{3}$ and other chemical elements per $10 \mathrm{~m}^{3}$ of filtered water for the headbox. Abrasive elements found in wastewater after purification through a filter station are found no more than $0.027 \mathrm{mg} / \mathrm{dm}^{3}$.

Thus, the use of an ozone-filtering station for water treatment in the production of fiberboards by feeding the wood fiber slurry through the headbox has a number of advantages.

Water preparation significantly reduces the amount of impurities and various inclusions in the water, which in turn reduces abrasive abrasion of the working surface of the inlet housing, reduces accumulation of crystalline particles in hard-to-reach areas of the equipment and reduces wear of working surfaces interacting with the water flow.

\section{References}

1. Begunkov O. I., Vyvodtsev N. V., Guryev V. V. The use of low-quality wood and waste from the woodworking industry: a practical guide to Khabar. GOS. Tech Publishing House. UN-TA, 132 p. 
2. Chistova N. G. Processing of wood waste in the technological process of obtaining wood-fiber boards : dis. ... doct. technical sciences. Krasnoyarsk, 2010. 415 p.

3. Alexandrov A.V., Alexandrova T. N. Rheology and hydrodynamics of the processes of ebb and paper formation. / 2nd ed., Hydrodynamics of the processes of paper formation: textbook. stipend. St. Petersburg, 2015. 133 p.

4. Solechnik N. Ya. Production of wood-fiber boards. M., 1963. 338 p.

5. Alexandrov A.V., Alashkevich Yu. D. Equipment for pulp and paper production / 2nd ed., paper-making machines: textbook. poso-bie. SPb., 2018. 99 p.

6. Khokhlacheva N. M. Corrosion of metals and measures of protection against corrosion. M., 2019. 118 p.

7. Bakhvalov G. T., Turkovskaya A.V. Corrosion and protection of metals. M.: Metallurgy, 1947. 400 p. 